\title{
Recobrimentos à base de carboximetilcelulose e dextrina em mangas 'Tommy Atkins' armazenada sob refrigeração
}

\author{
Coatings based on carboximethyl cellulose and dextrin in 'Tommy Atkins' mango fruit stored \\ under refrigeration
}

\section{Andréia Amariz $^{\mathrm{F}^{*}}$ Maria Auxiliadora Coêlho de Lima ${ }^{\mathrm{II}}$ Danielly Cristina Gomes da Trindade ${ }^{\mathrm{II}}$ Ana Cristina Nascimento dos Santos ${ }^{\mathrm{I}}$ Thalita Passos Ribeiro ${ }^{\mathrm{I}}$}

RESUMO

Objetivou-se avaliar a eficiência de recobrimentos à base de carboximetilcelulose $(C M C)$ e dextrina em manga 'Tommy Atkins' armazenada durante zero, dez e 20 dias sob refrigeração $\left(12,4 \pm 3,1^{\circ} \mathrm{C}\right.$ e $72 \pm 12 \%$ UR) e, posteriormente, submetida às condições de ambiente $\left(20,3 \pm 3,0^{\circ} \mathrm{C}\right.$ e $40 \pm 7 \%$ $U R$ ) por três, seis, oito e nove dias. Os recobrimentos CMC $1,0 \%+$ dextrina $0,2 \%$, CMC $0,8 \%+$ dextrina $0,5 \%$ e $C M C$ $0,5 \%+$ dextrina $1,0 \%$ foram comparados ao controle. $O$ delineamento experimental foi inteiramente casualizado, em fatorial $4 x 7$ (recobrimento x tempo de armazenamento), com quatro repetições compostas por três frutos. A aplicação de CMC $1,0 \%$ + dextrina $0,2 \%$ ou CMC 0,8\% + dextrina $0,5 \%$ retardou o acúmulo de sólidos solúveis, a redução da acidez titulável e a evolução da cor da casca, com incremento no brilho superficial dos frutos, o que garantiu melhor aparência. Os efeitos indicam atraso da maturação, sendo mais evidentes no tratamento $C M C 0,8 \%+$ dextrina $0,5 \%$.

Palavras-chave: Mangifera indica, atmosfera modificada, póscolheita, películas comestiveis, qualidade.

\section{ABSTRACT}

It was aimed to evaluate the efficiency of coatings based on carboximethyl cellulose (CMC) and dextrin applied in 'Tommy Atkins' mango fruit stored for zero, ten and 20 days under refrigeration $\left(12.4 \pm 3.1^{\circ} \mathrm{C}\right.$ and $\left.72 \pm 12 \% \mathrm{RH}\right)$ and, after this period, submitted to ambient conditions $\left(20.3 \pm 3.0^{\circ} \mathrm{C}\right.$ and $40 \pm 7 \%$ RH) for three, six, eight and nine days. The CMC $1.0 \%$ + dextrin $0.2 \%$, CMC $0.8 \%+$ dextrin $0.5 \%$ and $C M C 0.5 \%+$ dextrin $1.0 \%$ coatings were compared to the control. The experimental design was completely randomized in factorial $4 \times 7$ (coating $x$ storage time), with four replicates constituted by three fruits. The application of CMC $1.0 \%+$ dextrin $0.2 \%$ or CMC $0.8 \%+$ dextrin $0.5 \%$ delayed the soluble solids accumulation, the titratable acidity reduction and the skin color evolution, increasing fruit brightness that ensured a better appearance. The responses indicate a delay on maturation that was more evident on CMC $0.8 \%+$ dextrin $0.5 \%$ treatment.

Key words: Mangifera indica, modified atmosphere, postharvest, edible coatings, quality.

\section{INTRODUÇÃO}

As condições climáticas predominantes no Brasil favorecem o cultivo da mangueira. Em algumas regiões, como o Vale do São Francisco, principal exportador brasileiro de manga, o cultivo é conduzido sob irrigação, adotando-se o estresse hídrico como componente do manejo, em fases fenológicas específicas. Para a mangueira, a regulação do estresse hídrico acelera e uniformiza a maturação dos ramos, estimulando a floração e permitindo a oferta da fruta em períodos comercialmente mais favoráveis (ALBUQUERQUE et al., 2002).

Essa diferenciação no manejo tem permitido atingir importantes mercados. Segundo VALEXPORT (2008), em 2007, a região exportou 107.812t de manga, o que representou $93 \%$ das exportações nacionais da fruta, gerando US\$ 83,2 milhões em receita. Os principais importadores da manga brasileira são os

'Fundação de Amparo à Ciência e Tecnologia do Estado de Pernambuco (FACEPE), Recife, PE, Brasil.

"Embrapa Semiárido, BR 428, Km 152, CP 23, 56302-970, Petrolina, PE, Brasil. E-mail: maclima@cpatsa.embrapa.br. *Autor para correspondência.

IIIEmbrapa Semiárido, Petrolina, PE, Brasil. 
mercados europeu e americano. Porém, desde 2005 registram-se aumentos nas exportações para o Japão, representadas por 401,6t, em 2007 (VALEXPORT, 2008).

Para atender às exigências sempre crescentes dos mercados e diversificá-los, uma vez que $70 \%$ do volume das exportações de manga estão concentrados principalmente na Europa (ANUÁRIO BRASILEIRO DE FRUTICULTURA, 2007), faz-se necessário investir em tecnologias que mantenham excelência no padrão de qualidade, minimizem perdas e aumentem a rentabilidade. Dentre as técnicas usadas para prolongar a vida útil e regular os processos fisiológicos e bioquímicos dos frutos, a fim de manter a qualidade durante o transporte e a estocagem, estão a refrigeração e as atmosferas controlada e modificada.

O armazenamento refrigerado é bastante utilizado por retardar os processos degradativos que ocorrem após a colheita. No entanto, em alguns casos, requer o uso de técnicas complementares, como as atmosferas controlada e modificada, para obtenção de melhores resultados. MOTA et al. (2006) destacaram que a composição da atmosfera ao redor do fruto influencia o amadurecimento. Ao diminuir os níveis de $\mathrm{O}_{2}$ e elevar os de $\mathrm{CO}_{2}$, desde que não resulte em anaerobiose, as reações de degradação e/ou síntese de substâncias no fruto são atrasadas, proporcionando maior vida útil (CHITARRA\& CHITARRA, 2005).

A atmosfera controlada é uma técnica reconhecida como de custo alto, tanto de instalação como de manutenção. Em face disso, a atmosfera modificada, por meio de filmes poliméricos e recobrimentos, vem sendo preferida, constituindo-se em alternativa de conservação de baixo custo relativo (CARVALHOFILHO et al., 2006).

Os recobrimentos consistem em suspensões de um agente espessante, que forma uma película ao redor do fruto, reduzindo a migração de vapor d'água e as trocas gasosas com o meio, incrementando o brilho superficial e reduzindo infecções (OLIVEIRA \& CEREDA, 2003; PEREIRA et al., 2006). Para a composição desses recobrimentos, além de proteínas e lipídeos, derivados da amilose ou da celulose (ambos carboidratos) têm sido utilizados como matéria-prima, por serem biodegradáveis e consumíveis ainda no fruto (GUEDES, 2007; SCANAVACA JÚNIOR et al., 2007). A carboximetilcelulose (CMC) e a dextrina, derivados da celulose e do amido, respectivamente, possuem excelentes propriedades para esse fim, sendo barreiras eficientes à permeação de $\mathrm{O}_{2}$ (CHITARRA \& CHITARRA, 2005).

Em manga, recobrimentos de fécula de mandioca, amido de milho, quitosana e cera de carnaúba têm sido testados (GUEDES, 2007; SCANAVACA JÚNIOR et al., 2007; HOA \& DUCAMP, 2008). HOA \& DUCAMP (2008), por exemplo, aplicando recobrimentos à base de cera de carnaúba e de lecitina em manga apontaram, respectivamente, redução da perda de massa e aumento da vida útil em três dias, sob condição ambiente.

Diante disso, objetivou-se avaliar a aplicação pós-colheita de suspensões à base de CMC e dextrina em mangas 'Tommy Atkins', durante o armazenamento refrigerado seguido de temperatura ambiente.

\section{MATERIAL E MÉTODOS}

Os frutos foram colhidos no estádio 2 de maturação (caracterizado pela cor verde clara da casca no ápice, polpa levemente amarela próximo à semente $\mathrm{e}$ teor de sólidos solúveis em torno de $7^{\circ} \mathrm{Brix}$ ), em pomar comercial da Empresa Copa Fruit, situada no município de Petrolina, e conduzidos ao Laboratório de Fisiologia Pós-Colheita da Embrapa Semiárido, onde foram selecionados e tratados para posterior avaliação.

As mangas foram lavadas em detergente e água corrente e tratadas com solução clorada $\left(60 \mathrm{mg} \mathrm{g}^{-1}\right)$ por cinco minutos. Após secas, foram imersas durante um minuto nas suspensões CMC $1 \%+$ dextrina $0,2 \%$ (I), CMC 0,8\% + dextrina 0,5\% (II) ou CMC $0,5 \%$ + dextrina $1 \%$ (III) e comparados ao controle (sem recobrimento, IV). Além dos carboidratos, todas as suspensões continham óleo de girassol $0,3 \%$, sorbato de potássio $0,01 \%$, etanol $0,05 \%$ e surfactante $0,01 \%$. Essas suspensões foram caracterizadas, apresentando teores de sólidos solúveis (SS) de 1,4²Brix. Os teores de sólidos totais determinados nos recobrimentos I, II

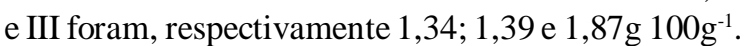
Por fim, foram observados valores de $\mathrm{pH}$ de 6,1 para os recobrimentos I e II e de 6,2 para III.

As mangas foram acondicionadas em caixas de papelão e avaliadas aos zero, dez e 20 dias sob refrigeração $\left(12,4 \pm 3,1^{\circ} \mathrm{C}\right.$ e $72 \pm 12 \%$ UR), que foi seguido de avaliações por mais três, seis, oito e nove dias em temperatura ambiente $\left(20,3 \pm 3,0^{\circ} \mathrm{Ce} 40 \pm 7 \% \mathrm{UR}\right)$.

Odelineamento experimental foi inteiramente casualizado, em fatorial $4 \times 7$ (recobrimento $x$ tempo de armazenamento), com quatro repetições compostas por três frutos. As variáveis analisadas foram: perda de massa (\%), obtida em balança semi-analítica pela diferença entre a massa no momento da colheita e nas respectivas datas de avaliação; cor da casca, determinada, na região verde e parte equatorial do fruto, por meio dos atributos luminosidade (L), croma (C) e ângulo de cor $(\mathrm{H})$, usando colorímetro digital portátil; 
cor da polpa, por meio de leitura dos atributos $\mathrm{L}, \mathrm{C} \mathrm{e} \mathrm{H}$, realizada à meia distância da casca e da semente, com colorímetro digital portátil; firmeza da polpa $(\mathrm{N})$, utilizando penetrômetro manual com ponteira de $8 \mathrm{~mm}$ de diâmetro; teor de SS ( ${ }^{\circ}$ Brix), obtido em refratômetro digital com compensação automática de temperatura (AOAC, 1998); açúcares solúveis totais (AST), quantificados usando o reagente antrona (YEMN \& WILLIS, 1954); acidez titulável (AT, g ácido cítrico. $\left.100 \mathrm{~mL}^{-1}\right)$, determinada por titulometria com solução de NaOH 0,1N (AOAC, 1998); e aparência, adotando-se escala subjetiva de notas proposta por LIMA et al., (2007), em que 4=fruto isento de manchas de senescência e com aparência fresca, 3=sinais de murcha inicial (perda de brilho e turgor) e/ou presença de manchas em até $5 \%$ da superfície do fruto, $2=$ manchas em 6 a $20 \%$ da superfície e/ou enrugamento inicial, $1=$ manchas em 21 a $40 \%$ do fruto e/ou avanço do enrugamento (intensidade moderada) e $0=$ manchas em mais de $40 \%$ da área do fruto e/ou enrugamento em intensidade severa e/ou podridão.

Os resultados foram submetidos à análise de variância e, quando o efeito dos recobrimentos foi significativo, as médias foram comparadas pelo teste de Tukey $(P \leq 0,05)$. Para avaliar os efeitos do tempo de armazenamento ou da interação entre os fatores, os resultados foram submetidos à análise de regressão polinomial. No último caso, realizou-se o desdobramento dos recobrimentos em cada tempo (BANZATTO \& KRONKA, 2006).

\section{RESULTADOS E DISCUSSÃO}

A perda de massa foi intensa após a mudança da temperatura de armazenamento (Figura 1A). Nas condições de refrigeração sob as quais os frutos encontravam-se armazenados, a perda de massa limitouse a $4 \%$ até a mudança para temperatura ambiente, que ocorreu ao $20^{\circ} \mathrm{dia}$, atingindo $7 \%$ no final do período.

$\mathrm{O}$ aumento na perda de massa pode estar relacionado à diminuição da umidade relativa de 72 para $40 \%$, decorrente da mudança de ambiente de acondicionamento dos frutos, neste estudo. Apesar de, em geral, a perda de massa de 5\% ser suficiente para promover murcha, a qualidade das mangas não foi comprometida, mantendo-se aptas à comercialização.

No que se refere ao uso de recobrimentos, aqueles elaborados a partir de polissacarídeos ou proteínas possuem excelentes propriedades mecânicas e óticas, alto coeficiente de permeabilidade ao vapor d'água e são sensíveis à umidade, ao contrário das películas à base de lipídios, que, apesar de proporcionarem uma barreira eficaz à perda de água, são opacas e pouco flexíveis, além de apresentarem sabor residual que pode influenciar as propriedades organolépticas dos alimentos (FONTES, 2005).

Um dos principais benefícios do uso de recobrimentos, conforme observações de FAKHOURI \& GROSSO (2003) e CHIUMARELLI \& FERREIRA (2006), foi a formação de uma barreira que limita a perda de vapor d'água. Segundo VILLALOBOS-CARVAJAL et al., (2009), esta resposta se deve à diminuição das taxas respiratórias. Porém, TOGRUL\& ARSLAN (2004) acrescentam que o desempenho do recobrimento depende da composição, das condições de armazenamento e do produto hortícola. No presente estudo, as combinações de CMC e dextrina não promoveram limitação à perda de água dos frutos.

A perda de firmeza da polpa ocorreu independentemente da aplicação dos recobrimentos, não sendo restringida sequer pela refrigeração (Figura 1A). Portanto, os eventos associados ao amaciamento dos tecidos, que modificam o tamanho e a distribuição dos polímeros das paredes celulares e ativam enzimas hidrolíticas, ocorreram normalmente.

Entretanto, respostas diferentes podem ser observadas. Em pesquisas realizadas com tomate, CHIUMARELLI \& FERREIRA (2006) afirmaram que é possível retardar o amaciamento da polpa quando se aplica alguns tipos de recobrimentos. Em se tratando de recobrimentos à base de amido, sua aplicação em pêssegos não influenciou a perda de firmeza (OLIVEIRA \& CEREDA, 2003), à semelhança das observações do presente estudo.

Atraso no amaciamento da polpa de manga 'Tommy Atkins' também foi obtido usando-se saco plástico de polietileno e bandeja de acetato recoberta com filme de PVC (cloreto de polivinila), com ou sem de permanganato de potássio (JERONIMO et al., 2007).

A variável $L$ representa o brilho superficial, podendo variar de 0 a 100 (desde cores escuras/opacas a cores brancas/máximo brilho). Os efeitos da aplicação de recobrimentos sobre a $L$ da casca foram observados principalmente quando os frutos foram transferidos para a temperatura ambiente (Figura 1B). A partir desta ocasião e até o $26^{\circ}$ dia, observou-se incremento no brilho dos frutos do controle e dos que receberam CMC $1,0 \%$ + dextrina $0,2 \%$ e CMC 0,5\% + dextrina $1,0 \%$, sendo que, neste último, não houve redução do brilho, alcançando valores médios de 47,19 ao final do período. A resposta sugere amadurecimento mais rápido nos frutos dos tratamentos citados. JACOMINO et al. (2003) também constataram aspecto transparente e maior brilho em goiabas revestidas com cera de carnaúba. Por outro lado, RIBEIRO et al. (2007) não observaram 


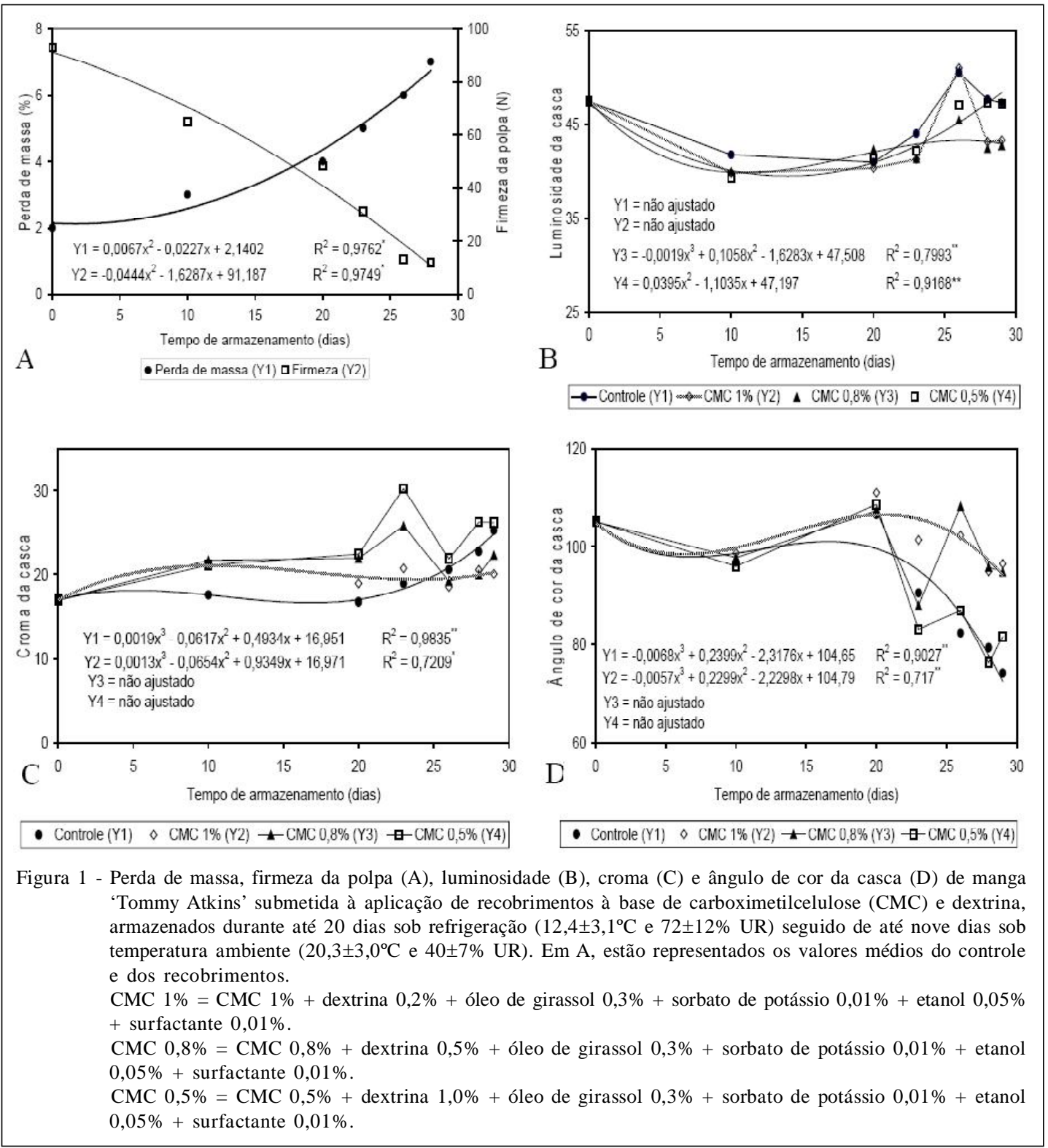

incremento do brilho em morango revestido com amido, carragenana e quitosana.

O brilho e a aparência são atributos importantes em frutas e hortaliças, tornando-se interessante o uso de películas comestíveis eficientes no incremento da luminosidade, que, em associação a outras características, pode favorecer a aceitação pelo consumidor.

Nos tratamentos controle e CMC $0,5 \%+$ dextrina $1,0 \%$, observou-se aumento nos valores de $\mathrm{C}$ da casca, indicando maior intensidade ou pureza da cor (Figura 1C). Esses tratamentos também resultaram em diminuição nos valores de $\mathrm{H}$ da casca durante o armazenamento, representando coloração amarela mais clara (Figura 1D). Por sua vez, houve atrasos da redução do valor de $\mathrm{He}$ do aumento de $\mathrm{C}$ nos tratamentos $\mathrm{CMC}$ $1,0 \%$ + dextrina $0,2 \%$ e CMC $0,8 \%$ + dextrina $0,5 \%$, ainda que no último se observasse resposta diferenciada nos primeiros dias sob temperatura ambiente. As causas devem estar relacionadas ao retardo da degradação da clorofila e/ou da síntese de carotenóides e flavonóides, o que sugere alguma interferência dos tratamentos no amadurecimento da manga. Estes resultados foram similares aos obtidos por PEREIRA et al. (2006), quando aplicaram fécula de mandioca em mamão Formosa 'Tainung1'. 
Entre os tratamentos, foram observadas diferenças restritas para $\mathrm{L}$ e $\mathrm{H}$ da polpa (dados não apresentados). Porém, os tratamentos CMC 0,8\% + dextrina $0,5 \%$ e CMC $0,5 \%$ + dextrina $1,0 \%$ proporcionaram coloração amarela mais clara na polpa, representada por valores de $\mathrm{H}$ correspondentes a $98 \mathrm{e}$ 94 , respectivamente. O croma da polpa dos frutos tratados com CMC $1,0 \%$ + dextrina $0,2 \%$ manteve-se menor em relação aos demais tratamentos no período do $20^{\circ}$ até o $26^{\circ}$ dia de armazenamento, quando as diferenças máximas foram de apenas 5,3 unidades (dados não apresentados). Após 28 dias, todos os tratamentos mostraram croma da polpa equivalentes.

O acúmulo de SS e de AST foi coerente com o amadurecimento da manga (Figura 2A). Apesar de os teores médios de AST terem sido menores nos frutos que receberam CMC $0,8 \%$ + dextrina $0,5 \%$, as diferenças estatísticas não resultariam em alteração do sabor no momento do consumo (Figura 2B). Possivelmente, a concentração desses compostos foi alterada durante o amadurecimento em decorrência da respiração, que oxida os carboidratos para a produção de energia. CHIUMARELLI \& FERREIRA (2006) não observaram efeito do uso de recobrimentos nos teores de SS durante o armazenamento de tomate. Da mesma forma, tratamentos com ceras e filmes plásticos não influenciaram o teor de AST em abacaxi 'Peróla' (SOUTO et al., 2004).

A diminuição da AT também foi mais lenta nos tratamentos CMC $1,0 \%$ + dextrina $0,2 \%$ e CMC
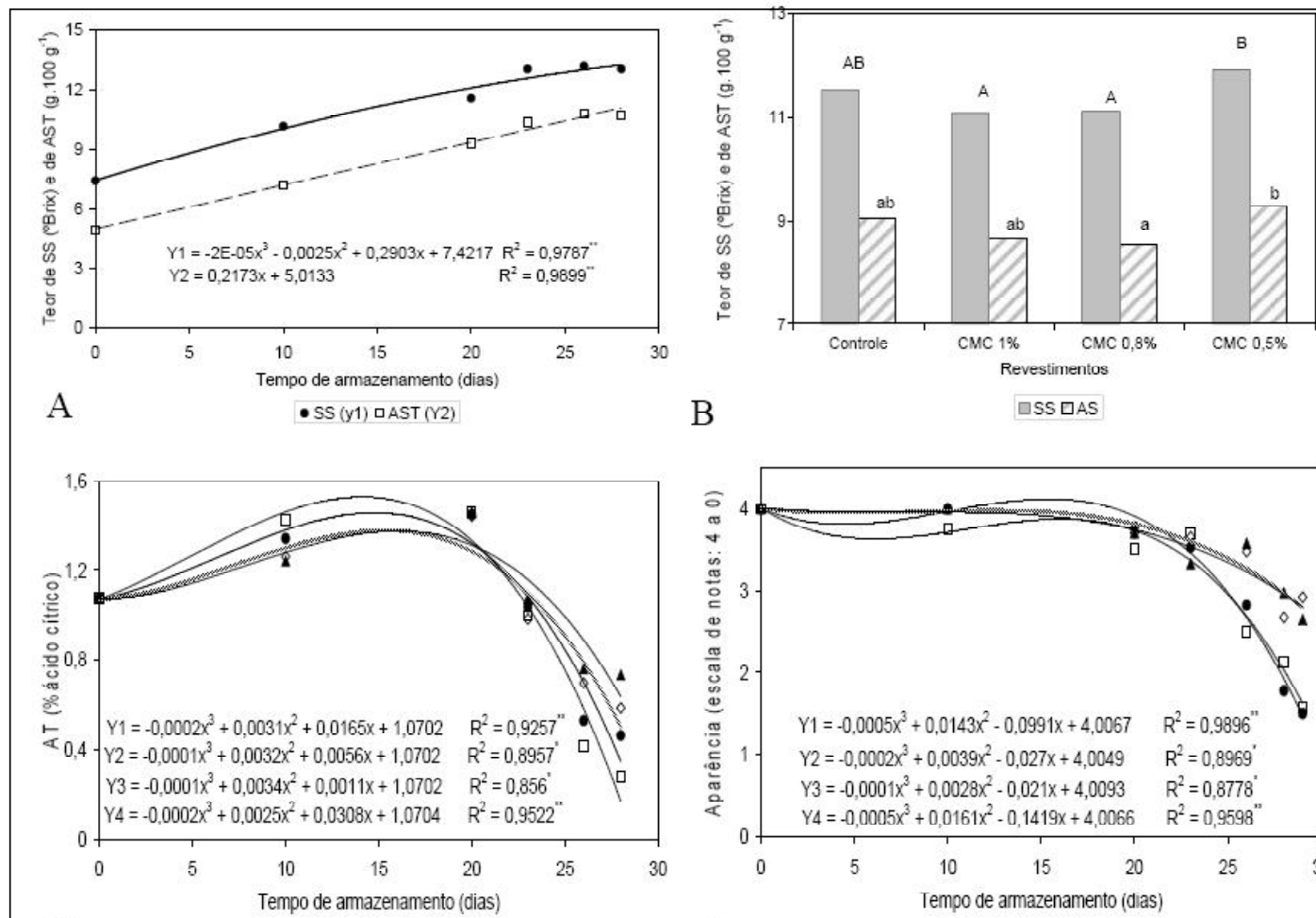

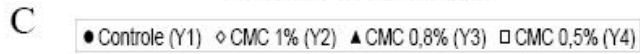

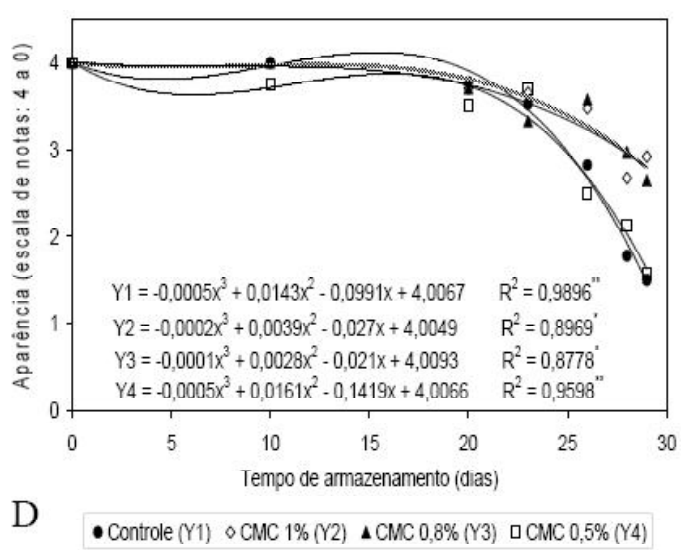

Figura 2 - Teor de sólidos solúveis - SS -, açúcares solúveis totais - AST - (A e B), acidez titulável - AT - (C) e aparência (D) de manga 'Tommy Atkins' submetida à aplicação de recobrimentos à base de carboximetilcelulose (CMC) e dextrina, armazenados durante até 20 dias sob refrigeração $\left(12,4 \pm 3,1^{\circ} \mathrm{C}\right.$ e $72 \pm 12 \%$ UR) seguido de até nove dias sob temperatura ambiente $\left(20,3 \pm 3,0^{\circ} \mathrm{C}\right.$ e $40 \pm 7 \%$ UR). Em A, estão representados os valores médios do controle e dos recobrimentos e, em $\mathrm{B}$, os valores médios dos tempos de armazenamento. Em $\mathrm{B}$, médias seguidas da mesma letra não diferem entre si pelo teste de Tukey $(P<0,05)$.

CMC $1 \%=$ CMC $1 \%$ + dextrina $0,2 \%$ + óleo de girassol $0,3 \%$ + sorbato de potássio $0,01 \%$ + etanol $0,05 \%$ + surfactante $0,01 \%$.

CMC $0,8 \%=$ CMC $0,8 \%$ + dextrina $0,5 \%$ + óleo de girassol $0,3 \%$ + sorbato de potássio $0,01 \%$ + etanol $0,05 \%$ + surfactante $0,01 \%$.

CMC $0,5 \%$ = CMC $0,5 \%$ + dextrina $1,0 \%$ + óleo de girassol $0,3 \%$ + sorbato de potássio $0,01 \%$ + etanol $0,05 \%$ + surfactante $0,01 \%$. 
$0,8 \%+$ dextrina $0,5 \%$ (Figura 2C). Essa resposta sugere que, nos frutos que receberam esses tratamentos, a concentração dos ácidos orgânicos foi um pouco mais alta, podendo influenciar o sabor. Geralmente, verificase diminuição na concentração desses ácidos no decorrer do amadurecimento, uma vez que são utilizados no Ciclo de Krebs, durante a respiração, e na síntese de novos compostos (CHITARRA \& CHITARRA, 2005). Ao utilizar cera de carnaúba e saco plástico poliolefínico em maracujá-amarelo, MOTA et al. (2006) observaram redução na AT, sugerindo provável variação negativa no sabor e flavor desses frutos. Ao contrário, recobrimentos com zeína e cera de carnaúba retardaram a diminuição da acidez em cerejas 'Ambrunés' (CARVALHO FILHO et al., 2006).

A aparência dos frutos tratados com CMC $1,0 \%$ + dextrina $0,2 \%$ e CMC $0,8 \%$ + dextrina $0,5 \%$ foi melhor, recebendo nota superior a 2,0 até o $29^{\circ}$ dia (Figura 2D). Porém, o tratamento CMC 0,8\% + dextrina $0,5 \%$ foi o mais eficiente já que, além da preservação da aparência comercial, também permitiu efeitos mais evidentes de atraso da maturação.

Ainda que CMC e dextrina sejam carboidratos solúveis em água em temperatura ambiente e biodegradáveis, o primeiro contribuiu mais efetivamente para a vida útil dos frutos uma vez que as melhores respostas foram observadas quando sua concentração foi maior.

\section{CONCLUSÃO}

O melhor recobrimento é CMC $0,8 \%+$ dextrina $0,5 \%$, que proporciona retardo da maturação e boa aparência às mangas mantidas a $20^{\circ} \mathrm{C}$ após armazenamento refrigerado.

\section{REFERÊNCIAS}

ALBUQUERQUE, J.A.S. de et al. Indução floral. In: GENÚ, P.J. de C.; PINTO, A.C. de Q. A cultura da mangueira. Brasília: Embrapa Informação Tecnológica, 2002. p.259-276.

ANUÁRIO BRASILEIRO DE FRUTICULTURA 2007. Santa Cruz: Gazeta Santa Cruz, 2007. 136p.

AOAC. Association of Official Analytical Chemists. Official methods of analysis. 15.ed. Washington, 1998. 1298p.

BANZATTO, D.A.; KRONKA, S.N. Experimentação agrícola. 4.ed. Jaboticabal: FUNEP, 2006. 237p.

CARVALHO FILHO, C.D. et al. Qualidade pós-colheita de cerejas cv. Ambrunés utilizando coberturas comestíveis. Revista Brasileira de Fruticultura, v.28, n.2, p.180-184, 2006. Disponível em: $<\mathrm{http}: / /$ www.scielo.br/scielo.php?script=sci_arttext\&pid=S0100$29452006000200006 \& \operatorname{lng}=\mathrm{en} \& n r m=i s o \& t \operatorname{lng}=\mathrm{pt}>$. Acesso em: 20 mar. 2009. doi: 10.1590/S0100-29452006000200006.
CHITARRA, M.I.F.; CHITARRA, A.B. Pós-colheita de frutas e hortaliças: fisiologia e manuseio. 2.ed. Lavras: UFLA, 2005. 785p.

CHIUMARELLI, M; FERREIRA, M.D. Qualidade pós-colheita de tomates 'Débora' com utilização de diferentes coberturas comestíveis e temperaturas de armazenamento. Horticultura Brasileira, v.24, n.3, p.381-385, 2006. Disponível em: <http:/ $/$ www.scielo.br/scielo.php? script $=$ sci_arttext\&pid $=$ S0102$05362006000300023 \& \operatorname{lng}=$ en\&nrm=iso\&tlng=pt $>$. Acesso em: 08 fev. 2009. doi:10.1590/S0102-05362006000300023.

FAKHOURI, F.M.; GROSSO, C. Efeito de coberturas comestíveis na vida útil de goiabas in natura (Psidium guajava L.) mantidas sob refrigeração. Brazilian Journal of Food Technology, v.6, n.2, p.203-211, 2003. Disponível em: <http:/ / www.ital.sp.gov.br/bj/artigos/html/busca/PDF/v6nu132a.pdf > . Acesso em: 10 out. 2008

FONTES, L.C.B. Uso de solução conservadora e de películas comestíveis em maçãs da cultivar Royal Gala minimamente processadas: efeito na fisiologia e na conservação. 2005. 118f. Dissertação (Mestrado em Ciência e Tecnologia de Alimentos) - Curso de Pós-Graduação em Ciência e Tecnologia de Alimentos,Escola Superior de Agricultura Luiz de Queiroz/Universidade de São Paulo (ESALQ/USP).

GUEDES, P. de A. Utilização de biofilme comestível na conservação pós-colheita de manga, cv. Rosa. 2007. $70 \mathrm{f}$. Dissertação (Mestrado em Fitotecnia) - Curso de Pós-Graduação em Agronomia, Universidade Estadual do Sudoeste da Bahia (UESB).

HOA, T.T.; DUCAMP, M.N. Effects of different coatings on biochemical changes of 'cat Hoa loc' mangoes in storage. Postharvest Biology and Technology, v.48, n.1, p.150-152, 2008. Disponível em: <http://www.sciencedirect.com/ science?_ob=ArticleURL\&_udi=B6TBJ-4R7CYRW$1 \& \_u s e r=7430124 \& \_c o v e r D a t e=04 \% 2 F 30 \% 2 F 2008 \& \_r d o c=21 \& \_f m t=$ high\&_orig=browse\&_srch=docinfo $(\% 23$ toc $\% 235144 \% 23200$ $8 \% 23999519998 \% 23680288 \% 23 \mathrm{FL} \mathrm{A}$ $\% 23$ display $\% 23$ Volume) \&_cdi $=5144 \&$ \& sort $=$ d\&_doc anchor $=$ \&_ct $=21 \&$ \&acct $=C 000012878 \&$ \&ersion $=1 \&$ \&urlV ersion $=0 \& \_$userid $=7430124 \&$ md5=9a8495340cb6bd70bb931e9608499537>. Acesso em: 25 fev. 2009. doi:10.1016/ j.postharvbio.2007.09.021.

JACOMINO, A.P. et al. Conservação de goiabas tratadas com emulsões de cera de carnaúba. Revista Brasileira de Fruticultura, v.25, n.3, p.401-405, 2003. Disponível em: $<$ http://www.scielo.br/scielo.php?script=sci_arttext\&pid=S0100$29452003000300010 \& \operatorname{lng}=$ en\&nrm $=i s o \& t \operatorname{lng}=\mathrm{pt}>$. Acesso em: 05 dez. 2008. doi: 10.1590/S0100-29452003000300010.

JERONIMO, E.M. et al. Qualidade de mangas Tommy Atkins armazenadas sob atmosfera modificada. Ciência e Agrotecnologia, v.31, n.4, p.1122-1130, 2007. Disponível em: <http://www.editora.ufla.br/site/_adm/upload/revista/31-42007_27.pdf>. Acesso em: 14 maio, 2010. doi: 10.1590/ S1413-70542007000400027.

LIMA, M.A.C. de et al. Armazenamento refrigerado de manga 'Tommy Atkins' sob atmosfera modificada (SmartbagTM). In: CONGRESO IBEROAMERICANO DE TECNOLOGÍA POSTCOSECHA Y AGROEXPORTACIONES, 5., 2007, Cartagena. Artigos completos... Cartagena: GPR/AITEP. 2007. p.1288-1296. 
MOTA, W.F. da et al. Uso de cera de carnaúba e saco plástico poliolefínico na conservação pós-colheita do maracujá-amarelo. Revista Brasileira de Fruticultura, v.28, n.2, p.190-193, 2006. Disponível em: <http:/ /www.scielo.br/scielo.php?script $=$ sci_arttext\&pid=S0100$29452006000200008 \& \operatorname{lng}=\mathrm{en} \& n \mathrm{~nm}=\mathrm{iso} \& \operatorname{lng}=\mathrm{pt}>$. Acesso em: 10 nov. 2008. doi:10.1590/S0100-29452006000200008.

PEREIRA, M.E.C. et al. Amadurecimento de mamão formosa com revestimento comestível à base de fécula de mandioca. Ciência e Agrotecnologia, v.30, n.6, p.1116-1119, 2006. Disponível em: <http://www.scielo.br/scielo.php?script=sci_arttext\&pid=S1413$70542006000600011 \& \operatorname{lng}=\mathrm{en} \& \mathrm{nrm}=\mathrm{iso} \& \mathrm{t} \operatorname{lng}=\mathrm{pt}>$. Acesso em: 10 nov. 2008. doi:10.1590/S1413-70542006000600011.

OLIVEIRA, M.A. de; CEREDA, M.P. Pós-colheita de pêssegos (Prunus persica L. Bastsch) revestidos com filmes a base de amido como alternativa à cera comercial. Ciência e Tecnologia de Alimentos, v.23, supl, p.28-33, 2003. Disponível em: <http:/ /www.scielo.br/scielo.php?script $=$ sci_arttext $\&$ pid $=$ S0101$20612003000400006 \& \operatorname{lng}=\mathrm{en} \& \mathrm{nrm}=\mathrm{iso} \& \mathrm{t} \operatorname{lng}=\mathrm{pt}>$. Acesso em: 20 mar. 2009. doi:10.1590/S0101-20612003000400006.

RIBEIRO, C. et al. Optimization of edible coating composition to retard strawberry fruit senescence. Postharvest Biology and Technology, v.44, n.1, p.63-70, 2007. Disponível em: <http:// www.sciencedirect.com/science?_ob=ArticleURL\&_udi=B6TBJ4 N1SP8F-1\&_user $=7430124 \&$ _coverDate $=04 \% 2 \mathrm{~F} 30 \% 2 \mathrm{~F}$ $2007 \&$ \&doc $=11 \&$ fmt $=$ High \&orig=browse \&_srch=docinfo ( $\% 23$ t o c \% $235144 \% 232007 \% 239995$ $59998 \% 23645930 \% 23$ FLA \%23 display\% 23 V o l u m e ) \&_ c d i $=5144 \&$ _ s o r t $=$ d \& _ d o c a n c hor $=\&$ _ $\mathrm{ct}=13 \& \&_{\text {_ a c } \mathrm{ct}=\mathrm{C} 0000} 0$ $12878 \&$ \&_version $=1 \&$ \&urlVersion $=0 \&$ \&_userid $=7430124 \&$ md5=b682bfcd919d252ae8981dff0e895820>. Acesso em: 10 out. 2008. doi: doi:10.1016/j.postharvbio.2006.11.015.

SCANAVACA JÚNIOR, L. et al. Uso de fécula de mandioca na pós-colheita de manga 'Surpresa'. Revista Brasileira de Fruticultura, v.29, n.1, p.67-71, 2007. Disponível em: <http:/ /www.scielo.br/scielo.php?script $=$ sci_arttext\&pid=S0100$29452007000100015 \& \operatorname{lng}=\mathrm{e} \mathrm{m} \& \mathrm{nrm}=\mathrm{i}$ so\&tlng=pt>. Acesso em: 08 abr. 2009. doi:10.1590/S0100-29452007000100015.
SOUTO, R.F. et al. Conservação pós-colheita de abacaxi 'Pérola' colhido no estádio de maturação "pintado" associando-se refrigeração e atmosfera modificada. Revista Brasileira de Fruticultura, v.26, n.1, p.24-28, 2004. Disponível em: <http:/ /www.scielo.br/scielo.php? script $=$ sci_arttext $\&$ pid $=S 0100$ $29452004000100008 \& \operatorname{lng}=\mathrm{e} \mathrm{m} \& \mathrm{nrm}=\mathrm{i}$ so\&tlng=pt $>$. Acesso em: 08 abr. 2009. doi:10.1590/S0100-29452004000100008.

TOGRUL, H.; ARSLAN, N. Extending shelf-life of peach and pear by using CMC from sugar beet pulp cellulose as a hydrophilic polymer in emulsions. Food Hydrocolloids, v.18, n.2, p.215-226, 2004. Disponível em: <http://www.sciencedirect.com/science?_ob= A r t i c 1 e U R L \&_u d i = B 6 V P $9-48$ P V M 17 $1 \&$ \& s e r $=7430124 \&$ \& cover Dat e $=03 \% 2$ F $31 \%$ $2 \mathrm{~F} 2004 \&$ \&doc $=4 \&$ fmt $=$ high \&_orig $=$ browse \&_srch $=$ docinfo(\%23 toc\%236201\%232004\%23999819997\%2347 $4895 \% 23$ FLA \%23 display $\% 23$ Volume) \&_cdi $=6201 \&$ \& sort $=$ d\&_docanchor $=\&$ \&_t $=19 \&$ \& acct $=\mathrm{C}$ $000012878 \&$ \& version $=1 \&$ \&urlVersion $=0 \&$ \&_userid $=7430$ 124\&md5=f0d971b46baac515f73d6928252baa1a>. Acesso em: 30 jul. 2009. doi:10.1016/S0268-005X(03)00066.

VALEXPORT. Há 19 anos unindo forças para o desenvolvimento do Vale do São Francisco e da fruticultura brasileira. Petrolina, [2008]. 17p.

VILLALOBOS-CARVAJAL, R. et al. Barrier and optical properties of edible hydroxypropyl methylcellulose coatings containing surfactants applied to fresh cut carrot slices. Food Hydrocolloids, v.23, n.2, p.526-535, 2009. Disponível em: $<\mathrm{h} \mathrm{t} \mathrm{t} \mathrm{p} \mathrm{:} \mathrm{/} \mathrm{/} \mathrm{w} \mathrm{w} \mathrm{w.} \mathrm{s} \mathrm{c} \mathrm{i} \mathrm{e} \mathrm{n} \mathrm{c} \mathrm{e} \mathrm{d} \mathrm{i} \mathrm{r} \mathrm{e} \mathrm{c} \mathrm{t.} \mathrm{c} \mathrm{o} \mathrm{m} \mathrm{/}$ science?_ob=ArticleURL\&_udi=B 6VP9-4S03RJR$2 \&$ \& user $=7430124 \&$ \& coverDate $=03 \% 2$ F $31 \% 2 \mathrm{~F}$ $2009 \&$ \&doc $=32 \&$ fmt $=$ high \&_orig $=$ browse \&_srch $=$ doc infor $\% 23$ toc $\% 236201 \% 232009 \% 2399976999$ $7 \% 23700261 \% 23 \mathrm{FLA} \% 23 \mathrm{disp} 1$ a y $\% 23 \mathrm{~V}$ olume)\&_cdi=6201\&_sort $=$ d\&_docanchor $=\&$ \&_t $=36$ \&_acct $=$ C000012878\&_version $=1 \&$ _urlVersion $=0 \&$ \& userid $=$ $7430124 \& \mathrm{md} 5=\mathrm{d} 9 \mathrm{f} 09 \mathrm{a} 603 \mathrm{bd} 752149 \mathrm{bd} 15 \mathrm{~b} 14 \mathrm{ee} 3 \mathrm{f} 4 \mathrm{bfa}>$. Acesso em: 30 jul. 2009. doi:10.1016/j.foodhyd.2008.02.008.

YEMN, E.W.; WILLIS, A.J. The estimation of carbohydrate in plant extracts by anthrone. Biochemical Journal, v.57, n.2, p.504-514, 1954. 